\title{
The efficacy of intrauterine devices for emergency contraception and beyond: a systematic review update
}

This article was published in the following Dove Press journal: International Journal of Women's Health

\author{
Norman D Goldstuck \\ Tik Shan Cheung \\ Department of Obstetrics and \\ Gynaecology, Faculty of Medicine and \\ Health Sciences, University of \\ Stellenbosch, Cape Town 7505, South \\ Africa
}

Background: The copper intrauterine device (IUD) is a very effective form of emergency contraception. The failure rate is about $0.1 \%$. IUDs are also very cost-effective when used as long acting-reversible contraception (LARC). The purpose of this review is to attempt to confirm these findings.

Methods: The references for this study were generated by entering the terms "intrauterine device" and "emergency contraception" in Medline, PubMed, Popline, Global Health and ClinicalTrials.gov. Chinese references were obtained from the Wanfang database. For the emergency contraception study, articles with a defined population who were followed up until outcome were eligible. Women who were adequately followed for at least 6 months were included in the long term arm of the study.

Results: There were 18 (of 228) studies which met our selection criteria and were conducted in five countries, between August 2011 and January 2018. There were 1720 insertions of seven types of copper IUD with a failure rate of $0.12 \%$. The maximum time from intercourse to IUD insertion was 14 days. The discontinuation rate at 12 months was over $20 \%$ in the long term studies.

Conclusion: There are now a combined total of 8550 reported insertions from two reviews with 8 pregnancies and a failure rate of $0.093 \%$. Copper IUDs remain an effective form of emergency contraception, for which they are under-promoted. The major limitation of the studies is the lack of data relating unprotected intercourse to the day of the cycle.

Keywords: emergency contraception, copper intrauterine device, long acting-reversible contraception, unintended pregnancy

\section{Introduction}

Unintended pregnancy remains a public health concern. It is due either to failure to use contraception, failure to use contraception correctly, or failure of the contraceptive method itself. Emergency contraception (EC) may be used shortly after unprotected intercourse where there has been a failure to use contraception or a known failure to use a method correctly.

There are two main types of EC methods, oral methods and copper bearing, intrauterine devices. The most commonly used oral methods are levonorgestrel (LNG) $1.5 \mathrm{mg}$ (Plan $\mathrm{B}^{\circledR}$, Teva Pharmaceuticals, Petach Tikva, Israel) and ulipristal acetate (UPA) $30 \mathrm{mg}$ (Ella One ${ }^{\circledR}$, HRA Pharma, London, UK) given as single doses. ${ }^{1}$ The second method is the insertion of a copper intrauterine device (Cu IUD) ${ }^{2}$ and more recently a combination of an oral method and an intrauterine device has been tried, this
Correspondence: Norman D Goldstuck Department of Obstetrics and Gynaecology, Faculty of Medicine and Health Sciences, University of Stellenbosch, Francie van Zyl Dr, Tygerberg Hospital, Bellville, Cape Town 7505 , South Africa

Tel +27823418200

Email nahumzh@gmail.com 
is the use of a $52 \mathrm{mg}$ levonorgestrel releasing intrauterine system (LNG-IUS 52mg) accompanied by the oral LNG method. ${ }^{3}$ Both oral and intrauterine methods appear to have low failure rates with pregnancy rates of $\sim 2-3 \%$ for oral LNG EC ${ }^{4}$ and $~ 1.4 \%{ }^{4}$ for UPA and $0.09 \%$ for $\mathrm{Cu}$ IUDs. $^{2}$ Failure rate and true efficacy are not the same. Oral methods act mainly by delaying ovulation. ${ }^{1}$ UPA is more effective than LNG in this regard and the efficacy for UPA is estimated to be $62-85 \%{ }^{5}$ and LNG $47-53 \%{ }^{5}$ The true efficacy of the copper IUD has not been established as there have not been enough studies relating the insertion date to the day of the cycle of unprotected intercourse(s), but appears to be very effective. Oral LNG should be used within $72 \mathrm{hrs}$ of a single act of coitus and UPA within $120 \mathrm{hrs}$. Since true efficacy rates require randomized studies, the true efficacy values for both types of emergency contraception can only be estimates and will remain unknown.

The copper IUD was initially recommended to be inserted within $120 \mathrm{hrs}$ of single or multiple acts of unprotected coitus within this period and this remains the position of the American College of Obstetricians and Gynecologists. ${ }^{2}$ The World Health Organisation, the Centers for Disease Control and Prevention, Atlanta, Georgia, USA and the UK Faculty of Sexual and Reproductive Healthcare specify that an IUD can be inserted beyond 5 days as long as the time of ovulation can be reasonably determined and is within the 5 day window. ${ }^{2}$ This may be too restrictive and more recent data suggest that it may be safe to insert an emergency IUD at any time during the cycle provided a high sensitivity pregnancy test is negative. ${ }^{6}$

The $\mathrm{Cu}$-IUD and LNG-IUS $52 \mathrm{mg}$ are long-acting reversible contraceptives (LARC). The benefits of using LARC methods for effective fertility control are well established. ${ }^{7}$ Despite this very few clinicians recommend $\mathrm{Cu}$-IUDs for emergency contraception. ${ }^{8}$ The purpose of this review is to update and extend previous information on the use of the copper IUD as EC.

\section{Materials and methods}

The reference list was generated by using some of the same methods as used in the first study except that PubMed was also searched but we were unable to obtain a search of the Weipu (Chinese) data base. The search included the following databases using the following terms:

Medline: "Contraception, Postcoital" [Mesh] AND "Intrauterine Devices" [Mesh],
PubMed; "intrauterine device" AND “emergency contraception",

Popline: "IUD" \& "Emergency Contraception",

Global Health: "intrauterine device" and "emergency contraception",

Clinicaltrials.gov: 'intrauterine device "AND "emergency contraception".

Wanfang data (Chinese): using the Chinese terms for "emergency contraception" and "intrauterine device".

All the Google Scholar citations for the initial systematic review ${ }^{2}$ were also searched as well as archived material. The references in the Chinese language articles were searched to find articles which might have been missed in the database. The review was conducted following the "Preferred reporting items for systematic reviews and meta-analyses" (PRISMA) method. ${ }^{9}$ The search included any peer-reviewed study published between August 2011 (the date of the end of the previous period of study) ${ }^{2}$ and January 2018. In addition any referenced study which was not previously entered in the original study was also eligible for inclusion. Only English and Chinese language studies were included but studies in other languages would have been eligible if they appeared in the databases. The methods used were similar to those of the previous study and no additional formal protocol was used.

This systematic review updates the first one from 2012. ${ }^{2}$ Studies which provided data on women of age 18-45 who requested emergency contraception after unprotected intercourse and for whom there was adequate follow up until after the next menstruation or absence thereof, six weeks post insertion were eligible if more than 10 participants received an IUD. The secondary analysis was to include follow up of standard IUD event rates after 6 months or longer and pregnancy data for those who discontinued the IUD after the initial cycle.

Primary eligibility included women who presented for emergency contraception and were provided with an IUD and in which the number of pregnancies and follow up was determined for the index cycle which was defined as the cycle in which emergency contraception was needed. Also included was the long-term follow-up results where available. Relevant articles were identified and abstracted by two independent reviewers (NDG and TC), using translated articles by the non-Chinese speaking reviewer. A common data entry form was used to capture publication language, country of origin, type(s) of IUD used, maximum time from unprotected coitus to device insertion, initial study enrolment, efficacy evaluable population, 
number of treatment failures (pregnancies), comparative method (if any) and its treatment failures.

A separate entry form was used for collecting data from those studies in which there was long term follow up, defined as six months or more. This included the usual event rate data for IUDs including pregnancy, medical removals, expulsion and termination of the method for any reason. Since the previous review methods of analysis have become more detailed and some papers had been subjected to secondary analysis. ${ }^{3}$ Great care was taken to ensure that data were not used more than once, but data from the secondary ${ }^{10}$ and in one instance tertiary analysis ${ }^{11}$ has been referred to where of interest. All the search and extracted data has been uploaded to the Open Science Framework (OFS) data repository (https://osf.io/84grx/files/). A summary of the search results is given in Figures 1 and 2.

\section{Analytical methods}

Risk of bias may be related to loss of follow up after the index cycle since the outcome is binary (failure or success in preventing pregnancy). The other source of bias is the relationship of the day of cycle of insertion to the outcome. This was also not explicitly stated in all studies but likely to have been biased against the IUD rather than the comparator group as discussed later. Long term follow up bias is also based primarily on lack of follow up, leading to uncounted method failure. Computation of $95 \%$ binomial confidence intervals (CI) for proportions was performed for the index cycle data using the Clopper-Pearson exact method. The Chi-Square test was used to determine homogeneity. Pooled data was used to calculate grouped confidence intervals after testing for homogeneity as in the previous study. ${ }^{2}$ Calculations were performed using EpiTools epidemiological calculators.

\section{Results}

\section{Search findings}

There were six new English language studies which met our inclusion criteria. ${ }^{3,12-16}$ Three were from the United States and one each from the United Kingdom, Sweden and Egypt. There is an ongoing study of the LNG-IUS $52 \mathrm{mg}$ as an emergency contraceptive but no results are yet available (Clinical Trials.gov Identifier: NCT01539720). There were two Chinese studies ${ }^{18,19}$ which were not discovered and therefore not included in the earlier systematic review ${ }^{2}$ and ten new Chinese language studies. ${ }^{20-29}$ The PRISMA flow diagrams which were used for the selection of the English language and Chinese language

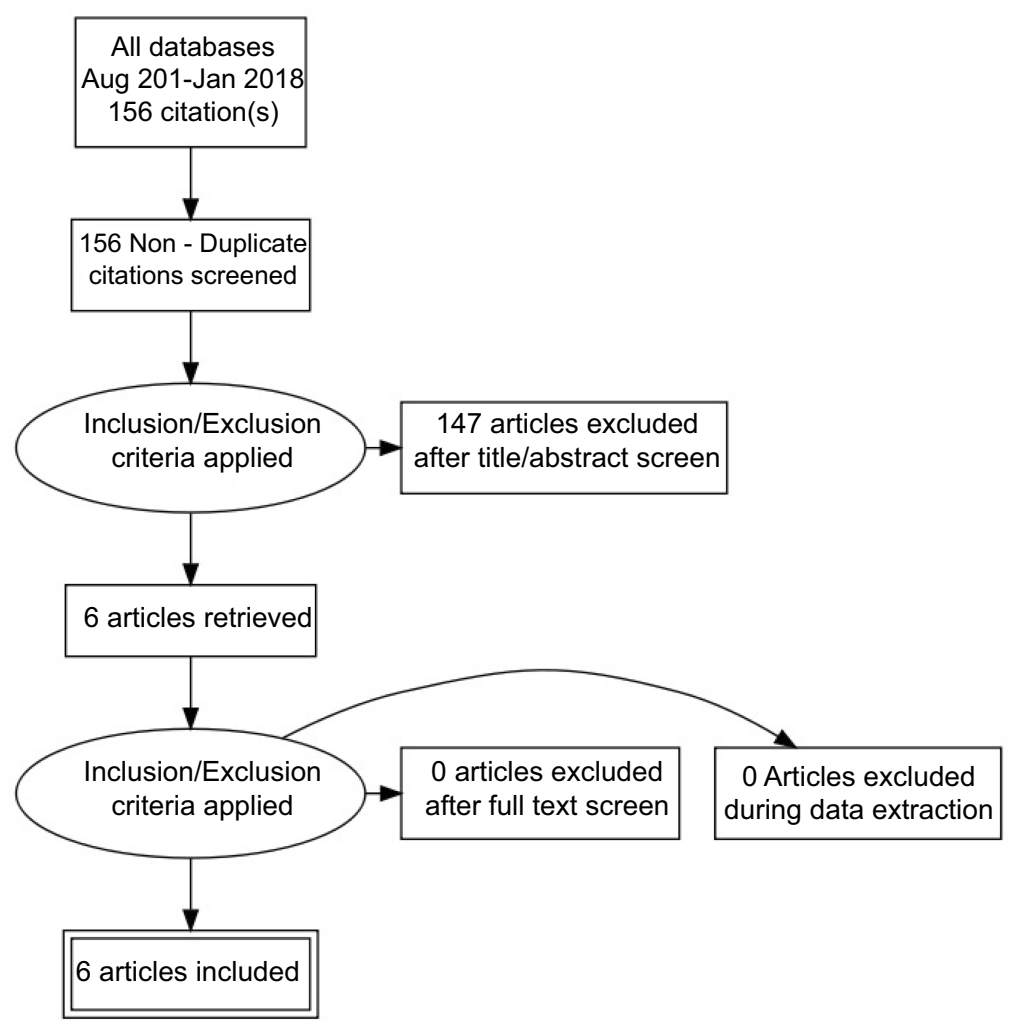

Figure I Algorithm for the selection of the English language studies. 


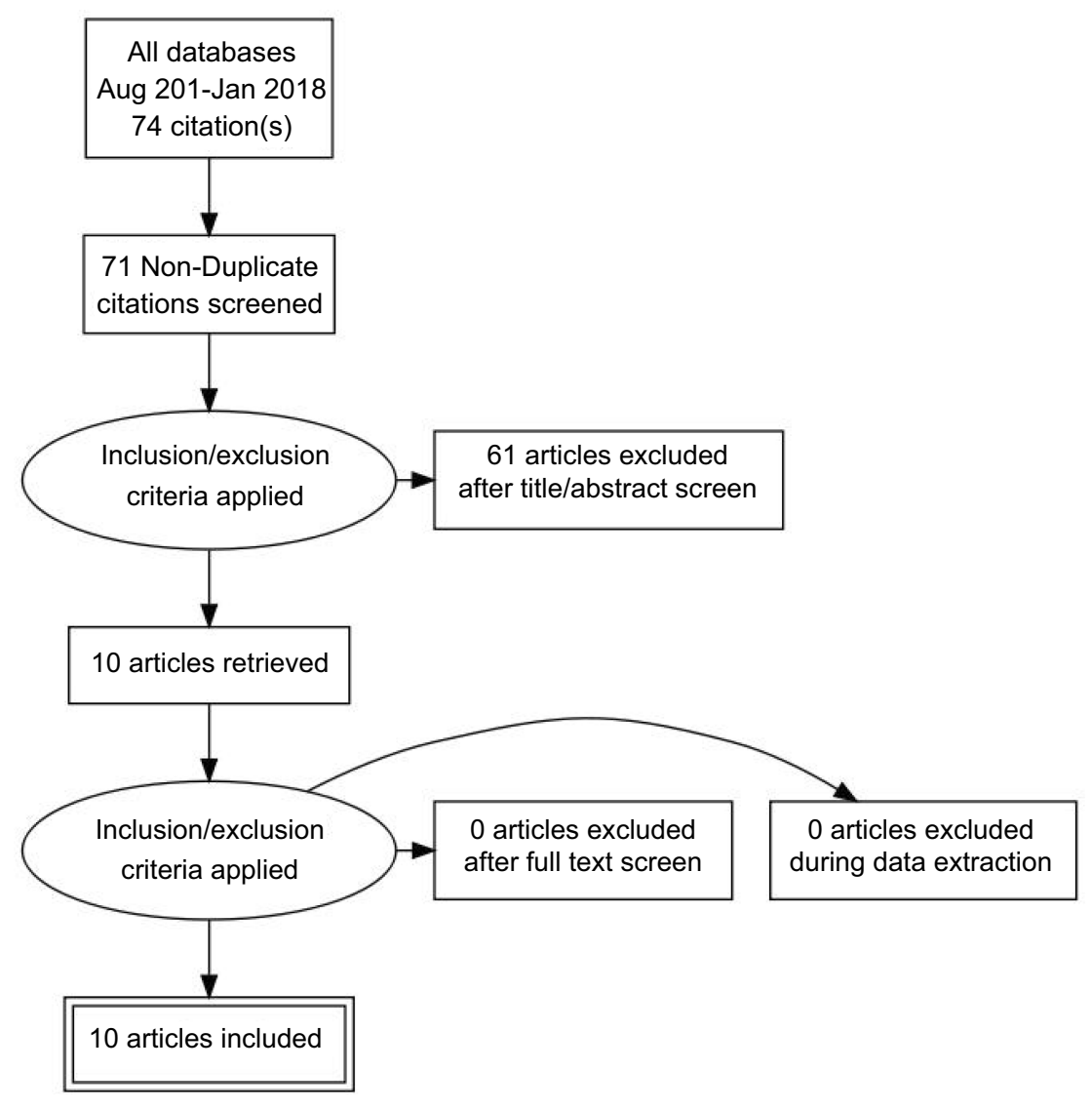

Figure 2 Algorithm for the selection of the Chinese language studies.

studies is provided in Figures 1 and 2. There was no specific foreign language search but we found no cross references and believe most if not all new studies would have been published in English or Chinese.

\section{Types of copper IUDs and comparative methods}

The copper bearing IUDs which were used included the Multiload copper $375 \mathrm{~mm}$ ( $\mathrm{MLCu}-375$, Multilan SA, Fribourg, Switzerland), the T copper 380A (TCu -380A, Paragard $^{\circledR}$, Teva Pharmaceuticals, Petah Tikva, Israel), the T copper 220mm (TCu -220, Janssen-Cilag, High Wycombe, Bucks, UK), the Copper gamma 220mm (Cu $\gamma$-220, Calliope, Shanghai, China), the Copper Yuan-gong + indomethacin (CuY-gong + indom, Yantai Jishengyaoxie Co. Ltd., Shandong, China) and the GyneFix 200 (GF-200, Contrel, Ghent, Belgium). In one study the levonorgestrel IUS containing $52 \mathrm{mg}$ of LNG (LNG-IUS 52mg, Mirena ${ }^{\circ}$, Bayer Pharma, Berlin, Germany, Levosert ${ }^{\odot}$, Lilletta ${ }^{\circledR}$ Actavis, Reykjavik, Iceland) in conjunction with oral LNG $1.5 \mathrm{mg}$ was used as a comparator to the copper IUD. The other cohort comparators included LNG $1.5 \mathrm{mg}$, UPA $30 \mathrm{mg}$ and mifipristone $10 \mathrm{mg}$, $25 \mathrm{mg}$, and $50 \mathrm{mg}$. The comparative oral methods will not be evaluated further. This review evaluates only the IUD arms of these studies.

\section{New studies}

A total of 16 studies (6 English language and 10 Chinese language) over 7 years compares favourably with the previously evaluated 42 (14 English and 28 Chinese) over 35 years $^{2}$ although this number should be augmented by the 2 missing studies. A list of all these studies is given in Table 1.

All of the Chinese studies except for two ${ }^{22,24}$ followed the usual protocol of limiting insertion to $120 \mathrm{hrs}$ (5 days) after unprotected intercourse. These two studies limited provision of an IUD to 3 days, probably to maintain similarity to the oral comparison group. All of the English language studies followed the same protocol (limiting insertion to $120 \mathrm{hrs}$ ) except the study by Sanders and colleagues ${ }^{10}$ which included subjects with multiple episodes of unprotected sex in the cycle pushing the length of time from first exposure to 6-14 days in some instances, provided a high sensitivity pregnancy test was negative.

None of the studies presented give adequate details of the cycle day of unprotected intercourse which makes 


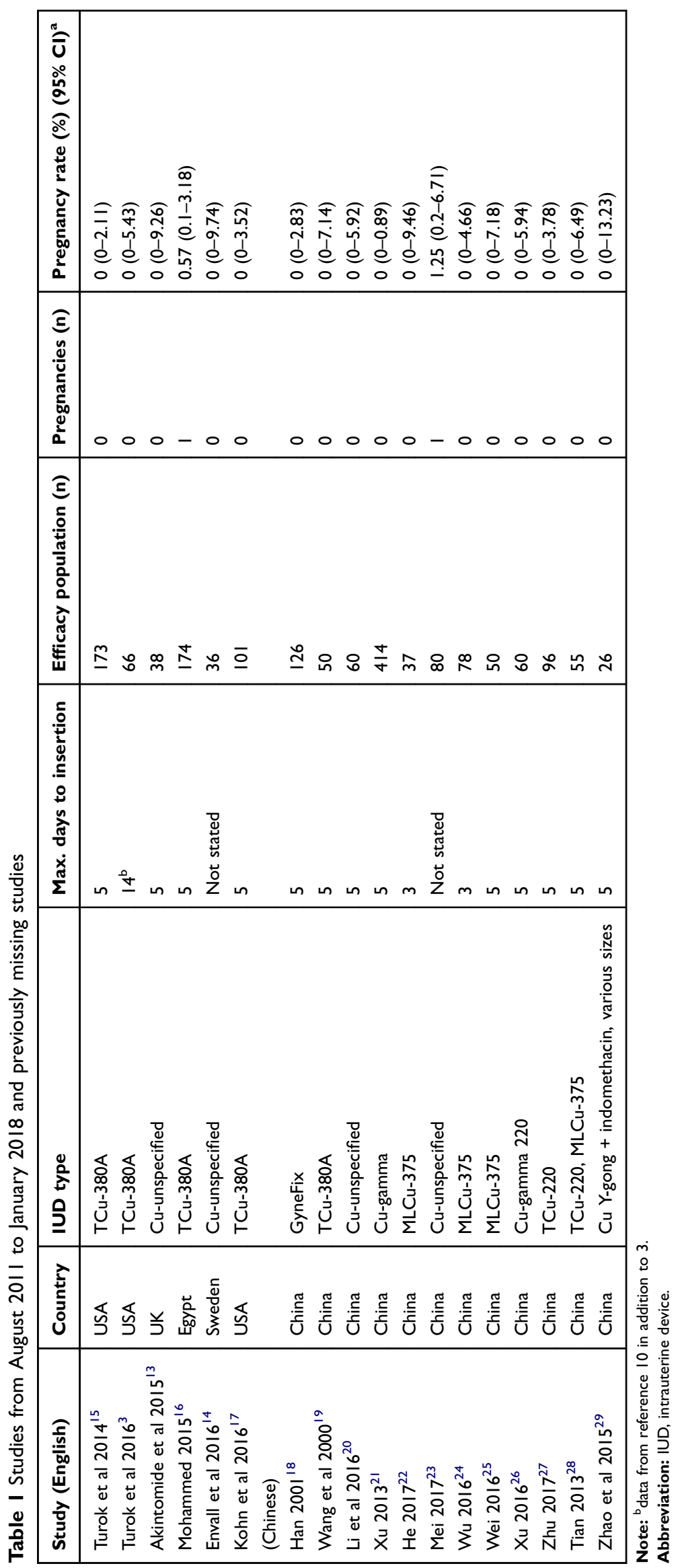


computation of even crude true efficacy estimates impossible. Three of the Chinese studies ${ }^{18,24,28}$ tried to give estimates of efficacy for the copper IUD and the comparator group using Dixon's method. ${ }^{30}$ The UK study was from multiple clinics and consisted of 103 patients of whom 64 were given oral EC and then the copper IUD as well, within 5 days. ${ }^{13}$ Only the 38 subjects who were not given oral EC have been included. There was no explanation given for this unusual approach in the paper but after consulting the authors it was because some of the subjects had first attended a clinic where IUD insertion facilities were not available. The Swedish study did not state the length of time after unprotected intercourse until the IUD was inserted. ${ }^{14}$ The overall quality of the evidence for all studies is level II-2 (Canadian task force on preventive health care).

\section{Index cycle results}

There were 588 insertions reported in the English language studies with one pregnancy with a failure rate of $0.17 \%$ (95\% CI $=0.0-0.1)$. There were 1132 insertions reported in the Chinese literature with one pregnancy with a failure rate of $0.09 \%(95 \% \mathrm{CI}=0.0-0.5)$. This is the same value previously reported. ${ }^{2}$ In total there were 1720 insertions with 2 pregnancies and a combined failure rate of $0.12 \%$ (95\% CI $=0.0-0.4)$. This confirms the findings of the earlier review2 The follow up rate of over $99 \%$ eliminates the uncertainty bias of unrecorded pregnancies.

These 1720 insertions with 2 pregnancies combined with the 6834 insertions and 6 pregnancies (excluding 4 pregnancies in one study from Egypt, which was considered to be an "outlier") from the earlier study ${ }^{2}$ gives a combined total of 8550 insertions with 8 pregnancies and a pregnancy rate of $0.093 \%(95 \% \mathrm{CI}=0.0-1.8)$ which is similar to the previous rate. ${ }^{2}$

\section{Long term follow up}

One of the earlier emergency IUD studies first noted that subjects who received an emergency IUD did not seem to want to keep it, ${ }^{31}$ although no specific reasons were given. There were 6 studies that attempted to follow up and document the subjects that received an emergency IUD after the index cycle. $^{3,15,21,22,29}$ The data is fairly sparse but in the US and Swedish studies the long term combination of expulsion and/ or discontinuation of the LARC method is high leading to an increased pregnancy rate of which most are probably not intended although this is not explicitly stated. Despite discontinuing the copper IUD, the copper IUD users were more likely to be using effective contraception (of another type) after 6 months than the UPA group in the Swedish study. ${ }^{14}$ The long term follow up rate was about $80 \%$. A summary of the long term follow up data is presented in Table 2.

\section{Discussion}

This study adds 1720 emergency Cu-IUD insertions to the first study of $7034 .^{2}$ In that study there was one report from Egypt which included 4 pregnancies and was a complete outlier. The data was therefore calculated with and without the Egyptian study to give a pregnancy rate of $0.09 \%$ (95\% $\mathrm{CI}=0.04-0.19 \%)^{2}$ which is the often quoted rate. The only pregnancy which was reported in an English language study in the new search was again from Egypt. This study has been included in our analysis so that there is a truly comparable pregnancy rate which is only very marginally higher $(0.12 \%)$ for this study compared to the previously reported rate where the Egyptian data was excluded. ${ }^{2}$ There are now a total of 8550 reported emergency IUD insertions and 8 pregnancies with a pregnancy rate of $0.093 \%$ from two reviews. The total is 12 pregnancies if we include the outlier study from Egypt in the first review for a pregnancy rate of $0.14 \%$. While this number appears to indicate that the emergency copper IUD

Table 2 Emergency intrauterine device (IUD) evaluation after 6 months or longer

\begin{tabular}{|c|c|c|c|c|c|}
\hline \multirow[t]{2}{*}{ Study } & \multirow[t]{2}{*}{ IUD } & \multirow[t]{2}{*}{ Follow up (months) } & \multicolumn{3}{|c|}{ Events (\%) } \\
\hline & & & \multicolumn{3}{|c|}{ Pregnancy $^{\mathrm{a}}$ Expulsion Discontinuation $^{\mathrm{b}}$} \\
\hline Turok et al $2014^{15}$ & TCu380A & 12 & $9(6)$ & 17 (1 I.4) & $37(24)$ \\
\hline Turok et al $2016^{3}$ & TCu380A & 12 & 0 & $6(9)$ & $15(22.3)$ \\
\hline Envall et al $2016^{14}$ & Cu IUD & 6 & I (2.7) & 0 & $8(22.2)^{c}$ \\
\hline Xu $2013^{21}$ & Cu Gamma & 6 & $3(0.72)$ & $20(4.8)$ & not stated \\
\hline $\mathrm{He} 2017^{22}$ & MLCu375 & 6 & $2(5.4)$ & 0 & 0 \\
\hline Zhao et al $2015^{29}$ & $\mathrm{Cu}$ Yuan gong + indomethacin & 12 & 0 & I (3.8) & 0 \\
\hline
\end{tabular}

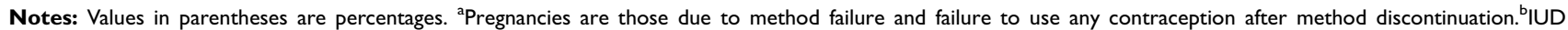
discontinuation is due to removal for medical and non-medical reasons. ${ }^{\mathrm{C}}$ The copper IUD was discontinued in favour of another method. 
provides good efficacy in preventing pregnancy it must be remembered that it is not possible to know how many pregnancies would have occurred in the absence of intervention.

Most of the new studies had comparison groups of an oral EC method. These studies were not randomised and not powered to detect any differences between the two methods. The pregnancy rates for the different oral methods were higher than that for the copper emergency-IUD. Furthermore, it is logically possible that in the absence of randomisation that the copper IUD was more likely to be given primarily to those for whom the risk of pregnancy was perceived to be greater by the providers; rather than because individual subjects preferred this method and wanted to initiate a copper IUD for emergency contraception and have the choice as to whether to continue with LARC contraception. This may have been a possible source of bias against the IUD as mentioned previously, however this is not explicitly stated in any of the studies and is conjectural.

In one study the LNG-IUS $52 \mathrm{mg}$ was given at the same time as oral $\mathrm{LNG}^{3}$ and there is no reason why this approach cannot be used together with LNG-IUS $13.5 \mathrm{mg}$ $\left(\right.$ Skyla $^{\odot} /$ Jaydess $^{(\mathcal{O}}$ ) or LNG-IUS $19.5 \mathrm{mg}\left(\right.$ Kyleena $\left.^{\circledR}\right)$ which may be more appropriate in nulliparous and uniparous women. ${ }^{32}$ While consideration has been given to using UPA as oral emergency contraception prior to providing an LNG releasing IUD $^{10}$ its role as a partial progestin agonist-antagonist may possibly interfere with the early action of the LNG-IUS, especially its pronounced effect on cervical mucus, ${ }^{33}$ in the same way that it influences the effect of desorgestrel containing oral contraceptives. ${ }^{34}$

Another approach is to use copper IUDs which are more likely to be tolerated. ${ }^{35}$ This is only practical in those countries which have multiple types of copper IUDs as options. This may help with the problems of expulsion and acceptability and enable emergency copper IUD users to continue to use the device as a LARC method. This is only achievable if the focus is not just on a copper IUD for emergency contraception but the most appropriate one. The provision of trained providers is especially important for preventing discontinuation of copper IUDs inserted as emergency contraception. Hopefully the manufacturers of the newer copper containing devices like the intrauterine ball (IUB-Ballerine ${ }^{\circledR}$ (Ocon Medical, Modiin, Israel) and VeraCept ${ }^{\circledR}$ (Contramed, Charlotte, North Carolina, USA) $)^{36}$ will complete pilot or larger studies of the IUD as EC to improve our knowledge of how different IUDs function in in this area.
During the early years following the introduction of the use of the copper IUD as an emergency contraceptive there was speculation as to whether it would have the same failure rate as when it was used as a LARC method. This followed an early case report of a failure ${ }^{37,38}$ of the method. The failure rate as an emergency contraceptive appears to be very much lower than the cumulative rate at 7 years for continuous use of the $\mathrm{TCu} 380 \mathrm{~A}$ of 2.5 per 100 woman years of use, ${ }^{39}$ suggesting a different immediate mechanism of action of the copper IUD when being used for emergency contraception compared to use as LARC contraception.

Further studies which focus on the day of cycle of insertion are necessary to determine true efficacy of the method. There is also another method of estimating true efficacy of the copper IUD as an emergency contraceptive. The efficacy of the main oral emergency contraceptive methods is reasonably established. ${ }^{5}$ It may be possible to calculate the relative risk of pregnancy for copper IUDs versus oral methods from the comparative studies to obtain an estimate of copper IUD efficacy.

\section{Conclusion}

This study confirms the findings of the previous review that over $99 \%$ of those that use a copper IUD as an emergency contraceptive method do not become pregnant. The true efficacy of the method however, remains elusive. Women who present to clinics or pharmacies for emergency contraception, as opposed to those who acquire it as OTC medication should be informed of the copper IUD option or at least be advised of continuing with LARC contraception. Expanding the availability of copper IUD emergency contraception to those women who have had multiple episodes of unprotected intercourse in the two weeks prior to requesting emergency contraception ${ }^{10}$ and who have negative high sensitivity pregnancy tests ${ }^{6}$ can help those women who are "too late" for oral emergency contraception. Careful choice of IUD may help to improve the continuation of emergency copper IUDs as a LARC method.

\section{Acknowledgment}

The help of Mr Gao Weiji of the Beijing National library for the Wanfang search is gratefully acknowledged. This review was unfunded.

\section{Disclosure}

The authors do not have any potential conflicts of interest in this work. 


\section{References}

1. Shen J, Che Y, Showell E, et al. Interventions for emergency contraception. Cochrane Database Syst Rev. 2017;(8):Art. No.: CD001324. doi:10.1002/14651858.CD001324.pub5

2. Cleland K, Zhu H, Goldstuck N, Cheng L, Trussell J. The efficacy of intrauterine devices for emergency contraception: a systematic review of 35 years of experience. Hum Reprod. 2012;27(7):1994-2000. doi:10.1093/humrep/des140

3. Turok DK, Sanders JN, Thompson IS, Royer PA, Eggebroten J, Gawron LM. Preference for and efficacy of oral levonorgestrel for emergency contraception with concomitant placement of a levonorgestrel IUD: a prospective cohort study. Contraception. 2016;93:526-532. doi:10.1016/j.contraception.2016.01.009

4. Armstrong C. ACOG Recommendations on Emergency Contraception. Am Fam Physician. 2010;82(100):1278.

5. Trussell J, Schwarz EB. Emergency contraception. In: Hatcher RA, Trussell J, Nelson A, Cates W, Stewart F, Kowal D, Polichar M, editors. Contraceptive Technology. New York, NY: Ardent Media; 2011; 113-145:

6. Turok DK, Godfrey EM, Wojdyla D, et al. Copper T380 intrauterine device for emergency contraception: highly effective at any time in the menstrual cycle. Hum Reprod. 2013;10(2):477-488.

7. Winner B, Peipert JF, Zhao Q, et al. Effectiveness of long-acting reversible contraception. $N$ Engl J Med. 2012;366:1998-2007. doi:10.1056/NEJMoa1110855

8. Harper CC, Speidel JJ, Drey EA, Trussell J, Blum M, Darney PD. Copper Intrauterine device for emergency contraception: clinical practice among contraceptive providers. Obstet Gynecol. 2012;119:220 226. doi:10.1097/AOG.0b013e3182429e0d

9. Moher D, Liberati A, Tetzlaff J, Altman DG; PRISMA Group. Preferred reporting items for systematic reviews and meta-analyses: the PRISMA statement. PLoS Med. 2009;6(7):e1000097. doi:10.1371/ journal.pmed.1000097

10. Sanders JN, Howell L, Saltzman HM, Schwarz EB, Thompson IS, Turok DK. Unprotected intercourse in the 2 weeks prior to requesting emergency intrauterine contraception. Am J Obstet Gynecol. 2016;215(5):592e1.592.e5. doi:10.1016/j.ajog.2016.06.028

11. Royer PA, Turok DK, Sanders JN, et al. Choice of emergency contraceptive and decision making regarding subsequent unintended pregnancy. $J$ Women's Health. 2016;25:1038-1043. doi:10.1089/jwh.2015.5625

12. Sanders JN, Turok DK, Royer PA, Thompson IS, Gawron LM, Storck KE. One-year continuation of copper or levonorgestrel intrauterine devices initiated at the time of emergency contraception. Contraception. 2017;96:99-105. doi:10.1016/j.contraception.2017.05.012

13. Akintomide H, Vinayagam S, Schunmann C. Emergency intrauterine device insertion in teenagers: an informal retrospective study. $J$ Famm Plann Reprod Health Care. 2014;40:196-199. doi:10.1136/ jfprhc-2013-100813

14. Envall N, Groes Kofoed N, Kopp-Kallner H. Use of effective contraception 6 months after emergency contraception with a copper intrauterine device or ulipristal acetate-a prospective observational cohort study. Acta Obstet Gynecol Scand. 2016;95:887-893. doi:10.1111/aogs.12916

15. Turok DK, Jacobsen JC, Dermish AI, et al. Emergency contraception with a copper IUD or oral levonorgestrel: an observational study of 1year pregnancy rates. Contraception. 2014;89:222-228. doi:10.1016/ j.contraception.2013.11.010

16. Mohammed ML. Acceptability and satisfaction towards Copper T $380 \mathrm{~A}$ versus single dose levonorgestrel as emergency contraception among Egyptian women. Egypt J Fertil Steril. 2015;19:34-40.

17. Kohn JE, Nucatola DL. EC4U: results from a pilot project integrating the copper IUC into emergency contraceptive care. Contraception. 2016;94:48-51. doi:10.1016/j.contraception.2016.02.008

18. Han Y. The clinical observation of the GyneFix IUD for emergency contraception. J Pract Obstet Gynecol. 2001;17:171-172. Chinese.
19. Wang C, Tiaan M, Shao M. A clinical comparative observation among copper IUD, low dose mifepristone and levonorgestrel for emergency contraception. J Chin Phys. 2000;2(5):271-273. Chinese.

20. Li J, Zhao M. Comparative effectiveness of three different methods of emergency contraception. J Guanxi Med Univ. 2016;33(2):308-309. Chinese.

21. Zhu C. Comparison of interval versus emergency IUD placement. China Health Care Nutr. 2013;23(4):1749-1750. Chinese.

22. He Y. Comparison of side effects of the copper IUD and LNG as emergency contraception. J Front Health. 2017;26(9):175. Chinese.

23. Mei X. Comparative analysis of the clinical effects of mifepristone, levonorgestrel and copper IUDs for emergency contraception. $J$ Chin Med. 2017;15(19):97-98. Chinese.

24. Wu TL. Comparison of the side effects of copper IUD and mifepristone in emergency contraception. Henan Med Res. 2016;25 (10):1835-1836. Chinese.

25. Wei M. Clinical efficacy of the copper containing IUD and mifepristone for emergency contraception. Chinese J Trauma Disability Med. 2016;24 (5):68-69. Chinese.

26. Xu P. Clinical comparison of copper IUD and LNG in emergency contraception. Zhongwai Nuxing. 2016;11:184-186. Chinese.

27. Zhu Y. Four different methods for emergency contraception. Guide China Med. 2017;15(11):24-25. Chinese.

28. Tian Z. Mifipristone and copper IUD in emergency contraception. China Health Care Nutr. 2013;23(9):5238. Chinese.

29. Zhao Y, Wang Y. Copper Yuan-gong+indomethacin for emergency contraception in 26 cases. Health All. 2015;2:165. Chinese.

30. Dixon GW, Schlesselman JJ, Ory HW, et al. Ethinyl estradiol and conjugated estrogens as postcoital contraceptives. JAMA. 1980;244:1336-1339. doi:10.1001/jama.1980.03310120024016

31. Black TRL, Goldstuck ND, Spence A. Post-coital intrauterine device insertion - a further evaluation. Contraception. 1980;22:653-658. doi:10.1016/0010-7824(80)90090-6

32. Goldstuck ND. Clarification of the role of the Jaydess (Skyla) LNGIUS $13.5 \mathrm{mg}$ and Kyleena LNG-IUS $19.5 \mathrm{mg}$ as intrauterine contraceptive systems. Expert Rev Med Devices. 2017;14(8):593-599. doi:10.1080/17434440.2017.1350169

33. Golstuck ND, Le HP. Delivery of progestins via the subdermal versus the intrauterine route: comparison of the pharmacology and clinical outcomes. Exp Opin Drug Deliv. 2018;15(7):717-727. doi:10.1080/ 17425247.2018.1498080

34. Brache V, Cochon L, Duikers IJ, et al. A prospective, randomised, pharmacodynamics study of quick-starting a desorgestrel progestin-only pill following ulipristal acetate for emergency contraception. Hum Reprod. 2015;30(12):2785-2793. doi:10.1093/humrep/dev241

35. Wildemeersch D, Pett A, Jandi S, Hasskamp T, Rowe P, Vrijens M. Precision intrauterine contraception may significantly increase continuation of use: a review of long-term clinical experience with frameless copper-releasing intrauterine contraception devices. Int $J$ Women's Health. 2013;5:215-225. doi:10.2147/IJWH

36. Hsia JK, Creinin MD. Intrauterine contraception. In: Hammond C editor. Innovations in Contraception Semin Reprod Med. Sacrimento. Thieme Medical Publishers, Sacramento, California, USA; 2016:2-9. doi:10.1055/s-0036-157438

37. Kubba AA, Guillebaud J. Failure of post-coital contraception after insertion of an intrauterine device. Case report. BJOG. 1984;91:596597. doi:10.1111/j.1471-0528.1984.tb04810.x

38. Goldstuck. Failure of post-coital contraception after insertion of an intrauterine device. Case report. BJOG. 1985;92:107. doi:10.1111/ j.1471-0528.1985.tb01058.x

39. Rowe P, Farley T, Peregoudov A, et al. Safety and efficacy in parous women of a 52-mg levonorgestrel-medicated intrauterine device: a 7year randomized comparative study with the TCu380A. Contraception. 2016;93:498-506. doi:10.1016/j.contraception.2016.0 2.024 


\section{Publish your work in this journal}

The International Journal of Women's Health is an international, peerreviewed open-access journal publishing original research, reports, editorials, reviews and commentaries on all aspects of women's healthcare including gynecology, obstetrics, and breast cancer. The manuscript management system is completely online and includes a very quick and fair peer-review system, which is all easy to use. Visit http://www.dovepress.com/testimonials.php to read real quotes from published authors. 